\title{
Study of Femoral Neck Anteversion and its Correlations in Bengali Population
}

MOULIK DEBNATH, SUDIPTO KONAR, PIYALI KUNDU, MADHUMITA DEBNATH

\begin{abstract}
Introduction: Anteversion is defined as the angle by which the femoral neck deviates forward from the axis of the femoral condyles. The angle of anteversion of the femoral neck varies widely. So, it is important to know the angle of anteversion in a particular population. The accurate estimation of femoral neck anteversion in living subjects has always been difficult, with many shortcomings and lack of reproducibility.
\end{abstract}

Aim: To estimate the average angle of femoral neck anteversion in Bengali population and to find its correlations with gender, side and stature.

Materials and Methods: Unpaired 100 dry femurs, 54 of male (33 right and 21 left) and 46 of female (17 right and 29 left), devoid of any gross pathology were used to measure the femoral anteversion angle by parallelogram method. Maximum femoral length was measured by using osteometric board and the data were statistically analyzed.
Results: Mean angle of anteversion was $20.05^{\circ}$ irrespective of sex and side. In case of male mean value for right side was $18.3^{\circ}$ and for left $21.61^{\circ}$. Mean values in female were $19.4^{\circ}$ for right side and $21.67^{\circ}$ for left side. Though in both males and females the mean values were higher in left sided bones; statistically significant difference was found in case of males only $(p<0.05)$. However, no statistically significant difference $(p>0.05)$ was found for the angle of anteversion between the male and female bones in the present study. A statistically significant correlation was found between angle of anteversion and maximum femoral length in both sex and sides with a $p$-value of $<0.01$.

Conclusion: The data established in this study will be useful for various orthopaedic procedures. Operative principles of hip prosthesis that capitalize on an impingement-free range of motion, achieving stability and preventing wear embrace an optimal femoral anteversion. This study will also be helpful in the fields of paleodemographic or other population studies and forensic anthropology.

\section{INTRODUCTION}

Structural architectural study of femur leads to recognition of torsion of the femoral neck. The neck of femur is laterally rotated with respect to shaft (the angle of anteversion) to some $10^{\circ}$ to $15^{\circ}$ although values of this angle vary amongst individuals and different populations [1]. Lower average anteversion of $7^{\circ}-8^{\circ}$ degrees were revealed in Caucasian skeletal surveys [2, 3] while greater average anteversion of $19^{\circ}$ was documented in African population [4, 5]. This variation of the angle is of paramount importance in orthopedic surgery (total joint replacement) to attain postoperative normal activity and performance of the concerned joints [6]. It is an important factor for longevity of the joints too.

However, femoral anteversion in human is not only an ordinary mark of evolutionary process but it results from torsional stresses passing through femoral neck during activities of daily living. This angle facilitates biomechanical advantageous bipedal postures during motion by reducing the horizontal bending forces experienced at hip and thereby reducing bony tensile stress. So this is very much clinically significant in hip replacement surgeries as proper placement of implants curtail bony strain around femoral component and thereby restricting the chances for implant loosening. It also increases the range of movement of the substitute without causing impingement and therefore enhances stability [6, 7].

Femoral anteversion is characterized by a posteriorly oriented femoral neck, which is closer than normal to the posterior part of acetabulum and related acetabular structures. This posterior extra-articular impingement results in reduced range of external rotation and tendency toward internal rotation during gait to keep the femoral head in the acetabular cavity. Researchers have focused on dynamic posterior impingement 
related considerations in coxa valga. Children with excessive femoral anteversion tend to sit with their feet outside them ('W' sitting) and walk with their toes turned in but they would find it difficult to sit cross-legged. Reduced degree of anteversion brings the anterior margin of the femoral neck closer to the anterosuperior acetabulum resulting in a tendency toward external rotation of the leg during gait. Such children can sit with their legs crossed and walk with their toes turned out. Researchers have focused on dynamic anterior impingement related considerations in coxa vara $[7,8]$.

The angle of anteversion is also dependent on the techniques employed used for its measurement. It is usually quantified as the angle between the proximal oblique axis of femur headneck and distal horizontal axis of lower end of femur. Lower values of anteversion can be accounted for using transepicondylar axis rather than retro-condylar axis as the distal axis [9].

To measure anteversion in living subjects there are many methods like imaging, clinical or intra-operative methods. Imaging techniques include fluoroscopy, biplane X-ray, axial $X$-ray, ultrasound, CT scan, Nuclear magnetic resonance and 3D remodeling. Clinical standard trochanteric prominence tests detects anteversion values slightly higher than the anteversion recorded on dried bones, this could be attributed to the overlying musculature. Intraoperative methods are most accurate and comparable to actual femoral anteversion [10].

But these techniques are not accessible in field situation. Also results of standard osteometric techniques are next best source and very close to above mentioned modern techniques. The present study is an attempt to evaluate the normal anteversion range in adult dry femora of West Bengal population. We also intend to see if there is any gender difference and right and left sided difference. Maximum femoral length is well documented representative of stature in diverse population groups as well as in Bengalis [11, 12]. We will also attempt to correlate stature of a person with anteversion angle.

\section{MATERIALS AND METHODS}

This cross-sectional observational study was carried out for 1 year during 2014-15. Total 100 dry adult femurs devoid of any gross pathology were obtained from Anatomy Department of various medical colleges of West Bengal; out of which 50 were of right side and 50 of left side. Maximum femoral length was measured by using osteometric board from the most superior point on the femoral head to the most inferior aspect of the medial condyle [Table/fig-1]. Sexing of femora was done by standard osteometric techniques followed by discriminant function analysis, which is a mathematical approach and extraordinarily valuable as sex discriminator [13].

For angle of anteversion proximal and distal axis were taken into account and the angle between them was measured.
The proximal axis was fixed by joining upmost point of head of femur and top most point of greater trochanter. The distal axis was held by joining the lowest point of lateral and medial condyle of femur. Along the axis metallic pins were set. The bone was suspended in bone hanging clamp [Table/fig-2] in anatomical position and anteversion angle was measured with the help of parallelograph [Table/fig-3] with standard technique [14]. Two metallic pins were fixed, which represented proximal and distal axes of femur. By using the vertical drop of the parallelograph, the impressions of the ends of the metallic pins were obtained as four points on a paper sheet placed on the floor. Of those four points, corresponding points were joined by pencil and resulting two lines symbolised the proximal and distal axis. The angle formed between these lines represented the angle of anteversion and was measured using a simple protractor [Table/fig-4].

All measurements were repeated by two independent observers to identify any intra and inter-observer variability.


[Table/Fig-1]: Maximum femoral length was measured by using osteometric board. (A-the most superior point on the femoral head, B- the most inferior aspect of the medial condyle)

[Table/Fig-2]: Bone hanging clamp [Table/Fig-3]: Parallelograph.

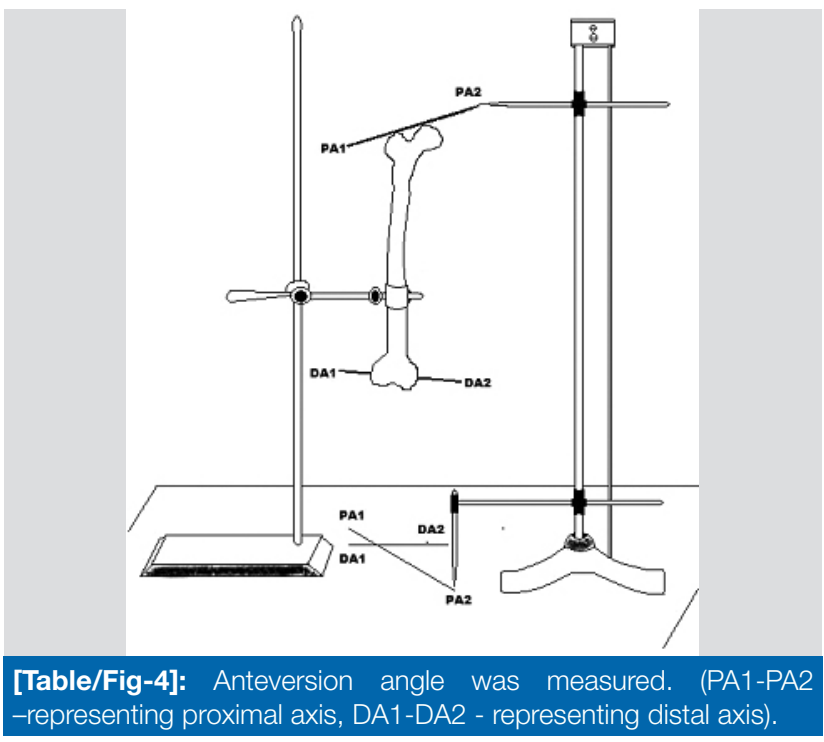


Data collected by this method was tabulated according to side and sex and was statistically analyzed.

\section{RESULTS}

Computation of ungrouped data for angle of anteversion (irrespective of sex and side) provided a mean value of $20.05^{\circ}$. Then data was grouped based on side of the bone, it showed mean angle of anteversion as $18.68^{\circ}$ for right and $21.42^{\circ}$ for left side. Student's t-test confirmed that anteversion values were significantly higher on the left side $(p<0.05)$ [Table/fig-5]. Computation of anteversion angle in case of male conferred mean value for right side as $18.3^{\circ}$ and for left as $21.61^{\circ}$. Mean values for anteversion angle in case of female were $19.4^{\circ}$ for right side and $21.67^{\circ}$ for left side [Table/fig-6].

Statistical evaluation of right and left anteversion angles in male and female femora elicited significant difference between right and left anteversion angle in male but not significant for the same in female. No significant sexual dimorphism was found between right and left anteversion angle of male and female [Table/fig-7]. Computation of maximum femoral length gave mean length for right as $44.9 \mathrm{~cm}$ and that for left as $44.5 \mathrm{~cm}$ [Table/fig-8]. Significant correlation was found between angle of anteversion and maximum femoral length in both sex and sides [Table/fig-9].

\section{DISCUSSION}

Average anteversion angle of femora in Bengali population is higher than that of several previous studies [15, 16] [Table/ fig-10]. Wolff's Law explains the remodeling in adult bone.

\begin{tabular}{|l|l|l|l|l|l|}
\hline $\begin{array}{l}\text { Angle of } \\
\text { anteversion }\end{array}$ & Mean & AD & SD & SE & $t$ \& p-value \\
\cline { 1 - 5 } $\begin{array}{l}\text { Ungrouped } \\
{[n=100]}\end{array}$ & $20.05^{\circ}$ & $4.72^{\circ}$ & $5.72^{\circ}$ & $0.57^{\circ}$ & - \\
\hline $\begin{array}{l}\text { Right } \\
{[n=50]}\end{array}$ & $18.68^{\circ}$ & $4.73^{\circ}$ & $5.67^{\circ}$ & $0.81^{\circ}$ & $\begin{array}{l}t=2.446 \\
p<0.05\end{array}$ \\
\cline { 1 - 4 } Left & $21.42^{\circ}$ & $4.61^{\circ}$ & $5.43^{\circ}$ & $0.77^{\circ}$ & \\
\hline
\end{tabular}

[Table/Fig-5]: Angle of anteversion of data grouped for right and left side irrespective of sex.

(AD average deviation, SD standard deviation, SE standard error)

\begin{tabular}{|c|c|c|c|c|c|}
\hline $\begin{array}{c}\text { Angle of } \\
\text { anteversion }\end{array}$ & Side & Mean & AD & SD & SE \\
\hline $\begin{array}{c}\text { Male } \\
{[\mathrm{n}=54]}\end{array}$ & $\begin{array}{c}\text { Right } \\
{[\mathrm{n}=33]}\end{array}$ & $18.30^{\circ}$ & $4.71^{\circ}$ & $5.55^{\circ}$ & $0.96^{\circ}$ \\
\cline { 2 - 6 } & $\begin{array}{c}\text { Left } \\
{[\mathrm{n}=21]}\end{array}$ & $21.61^{\circ}$ & $4.49^{\circ}$ & $5.22^{\circ}$ & $1.16^{\circ}$ \\
\hline $\begin{array}{c}\text { Female } \\
{[\mathrm{n}=46]}\end{array}$ & $\begin{array}{c}\text { Right } \\
{[\mathrm{n}=17]}\end{array}$ & $19.4^{\circ}$ & $4.74^{\circ}$ & $5.91^{\circ}$ & $1.47^{\circ}$ \\
\cline { 2 - 6 } & $\begin{array}{c}\text { Left } \\
{[\mathrm{n}=29]}\end{array}$ & $21.67^{\circ}$ & $4.85^{\circ}$ & $5.58^{\circ}$ & $1.05^{\circ}$ \\
\hline
\end{tabular}

[Table/Fig-6]: Angle of anteversion according to sex for right and left side.

(AD average deviation, SD standard deviation, SE standard error)

\begin{tabular}{|l|c|c|c|}
\hline \multicolumn{1}{|c|}{ Variable } & Male & Female & $\begin{array}{c}\text { t- value } \\
\mathrm{p} \text {-value }\end{array}$ \\
\hline $\begin{array}{l}\text { Right } \\
(\mathrm{mean} \pm \mathrm{SD})\end{array}$ & $18.3^{\circ} \pm 5.55^{\circ}$ & $19.4^{\circ} \pm 5.91^{\circ}$ & $\begin{array}{l}\mathrm{t}=0.6768 \\
\mathrm{p}>0.05\end{array}$ \\
\hline $\begin{array}{l}\text { Left } \\
\text { (mean } \pm \mathrm{SD})\end{array}$ & $21.61^{\circ} \pm 5.22^{\circ}$ & $21.67^{\circ} \pm 5.58^{\circ}$ & $\begin{array}{l}\mathrm{t}=0.2318 \\
\mathrm{p}>0.05\end{array}$ \\
\hline $\begin{array}{l}\text { t-value } \\
\mathrm{p} \text { - value }\end{array}$ & $\begin{array}{l}2.1568 \\
<0.05\end{array}$ & $\begin{array}{l}1.1341 \\
>0.05\end{array}$ & - \\
\hline Significance & Significant & Not significant & $\begin{array}{l}\text { Both non } \\
\text { significant }\end{array}$ \\
\hline
\end{tabular}

[Table/Fig-7]: Statistical comparison of right and left anteversion angle in male and female femora.

\begin{tabular}{|l|c|c|c|c|}
\hline \multirow{2}{*}{ Side } & \multicolumn{2}{|c|}{ Male } & \multicolumn{2}{c|}{ Female } \\
\cline { 2 - 5 } & Mean & SD & Mean & SD \\
\hline \multirow{2}{*}{ Right } & Mean & SD & Mean & SD \\
\hline Left & $44.9 \mathrm{~cm}$ & $1.80 \mathrm{~cm}$ & $39.47 \mathrm{~cm}$ & $3.72 \mathrm{~cm}$ \\
\hline
\end{tabular}

[Table/Fig-8]: Statistical comparison of right and left femoral length in male and female femora.

\begin{tabular}{|l|c|c|c|c|}
\hline \multirow{2}{*}{ Side } & \multicolumn{2}{c|}{ Male } & \multicolumn{2}{c|}{ Female } \\
\cline { 2 - 5 } & r-value & p-value & r-value & $p$-value \\
\hline Right & 0.874 & $<0.001$ & 0.916 & $<0.001$ \\
\hline Left & 0.901 & $<0.001$ & 0.816 & $<0.001$ \\
\hline
\end{tabular}

[Table/Fig-9]: Pearson's correlation coefficient $(r)$ of right and left anteversion angle with maximum femoral length in male and female.

The femur twists from torsional forces applied perpendicular to the epiphyseal growth plate. Femoral neck anteversion may develop because of changes in the stress placed on the adult femur diaphysis. Populations which are more accustomed in different ground level activities require an internally rotated posture or gait to keep the femoral head in. This may result torsion in the femoral neck which rotates it to the anterior side. Ground level activities are common and popular among Bengalis particularly in rural Bengal. Different ground level activities include squatting, eating, mopping, laundry, cooking etc, and even there is preference of floor sitting during leisure and rest periods. This is possible explanation for higher anteversion values in Bengalis [17-20].

Our study shows a significant difference $(p<0.05)$ between two side's anteversion values as right side shows lower value. Thus the present study opposes the hypothesis that both limbs are symmetrical. This is in line with previous studied on Indians [15, 16] though some western researchers had opined the reverse [21, 22]. Further grouping in this study revealed there was a significant difference at 5\% level between the right and left side anteversion values in male but not in female. Angle of anteversion is known to show sexual dimorphism. It is more in males as compared to females. Though in the present study the value of anteversion angle was higher in the female 
type bones, no statistically significant difference was found for the angle of anteversion between the male and female bones. This is matching with previous authors like Kingsley and Olmsted who observed a negligible gender difference $\left(0.081^{\circ}\right)$ [22] and Srimathi et al., who found no significant male-female difference [16]. As the bones were not paired in this study hence this inference cannot be stated with assertion.

Computed coefficient of correlation values between anteversion angle and femoral length on the right side and left side for male and female are all significant ( $p<0.001)$. Hamill also stated about increase in bone lengths and accompanying lower extremity adjustments to consequence excessive anteversion [23]. Valmassy opined that torsion of femur often demonstrate angle of gait changes which seem to respond to overall growth spurts and increases in height Growth spurts not only affect the length of the long bones but are also responsible for contributing in part to transverse plane alterations resulting increased anteversion [24].

\begin{tabular}{|c|c|c|c|c|}
\hline Author & Population & Year & Method & $\begin{array}{l}\text { Mean Anteversion } \\
\text { Angle (0) }\end{array}$ \\
\hline \multirow[t]{2}{*}{$\begin{array}{l}\text { Jain et al., } \\
\text { [25] }\end{array}$} & \multirow[t]{2}{*}{$\begin{array}{l}\text { India } \\
\text { (Delhi) }\end{array}$} & \multirow[t]{2}{*}{2003} & $\begin{array}{l}\text { Kingsley } \\
\text { Olmsted }\end{array}$ & $\begin{array}{l}8.1 \\
{[\text { male- } 7.5, \text { female- } 10.5 \text {, }} \\
\text { right }-7.3 \text {, left }-8.9]\end{array}$ \\
\hline & & & Parallelograph & $\begin{array}{l}8.3 \\
\text { [male- } 7.7, \text { female- } 10.8, \\
\text { right }-7.5 \text {, left }-9.2]\end{array}$ \\
\hline $\begin{array}{l}\text { Badjatiya et } \\
\text { al., [26] }\end{array}$ & \begin{tabular}{|l|} 
India \\
(Udaipur)
\end{tabular} & 2014 & $\begin{array}{l}\text { Kingsley } \\
\text { Olmsted }\end{array}$ & $\begin{array}{l}18.67 \\
\text { [male- 16.67, female- } \\
21.30]\end{array}$ \\
\hline $\begin{array}{l}\text { Srimathi } \\
\text { et al., [16] }\end{array}$ & $\begin{array}{l}\text { India } \\
\text { (Chennai) }\end{array}$ & 2012 & $\begin{array}{l}\text { Kingsley } \\
\text { Olmsted }\end{array}$ & $\begin{array}{l}9.8 \\
\text { [male- } 9.78, \text { female- } \\
9.79, \text { right- } 9.49, \text { left- } \\
10.13]\end{array}$ \\
\hline $\begin{array}{l}\text { Zalawadia } \\
\text { et al., [18] }\end{array}$ & $\begin{array}{l}\text { India } \\
\text { (Gujrat) }\end{array}$ & 2010 & $\begin{array}{l}\text { Kingsley } \\
\text { Olmsted }\end{array}$ & $\begin{array}{l}9.0 \\
\text { [male- } 7.2 \text {, female- } 10.5]\end{array}$ \\
\hline \multirow{2}{*}{$\begin{array}{l}\text { Lausten et } \\
\text { al., [27] }\end{array}$} & \multirow[t]{2}{*}{ Denmark } & 1989 & Ultrasound & 23.4 \\
\hline & & & CT Scan & 13.5 \\
\hline $\begin{array}{l}\text { Sugano } \\
\text { et al., [28] }\end{array}$ & Japan & 1998 & $\begin{array}{l}\mathrm{D} \\
\text { reconstruction }\end{array}$ & 19.8 \\
\hline $\begin{array}{l}\text { Present } \\
\text { study }\end{array}$ & \begin{tabular}{|l} 
India \\
(Bengali)
\end{tabular} & 2015 & Parallelograph & $\begin{array}{l}20.5 \\
\text { [right }-18.68 \text {, left - } \\
21.42]\end{array}$ \\
\hline
\end{tabular}

Populations differ from each other in size and proportions and these differences can affect the metric assessment of femoral anteversion [5]. Forensic anthropologists are constantly attempting to improve the methods of osteological data analysis by performing fine-tuning of existing methods through developing population specific standards. Particular measurement of femoral neck anteversion is also important in various orthopaedic diagnosis and procedures though this measurement in living subjects has always been complicated with several limitations. $[10,11,15]$. Thus, the present study will be able remove the lacuna of information about femoral neck anteversion in Bengali and enthuse biomechanical engineers regarding implant design.

Any deviation from normal range of femoral anteversion is related with different disease conditions. These problems vary from minor postural defects in children to immobilising hip osteoarthritis in adults. Perthes disease, cerebral palsy, poliomyelitis, apparent genu valgum, external tibial torsion, flat foot etc are related with increased anteversion angle whereas toing out, rickets, chondrodystrophy are related with decreased anteversion angle. Thus accurate measurement of anteversion angle is crucial for diagnosis as well as for corrective procedures as femoral derotation osteotomy $[7,8,14-16]$

\section{CONCLUSION}

In the present study the mean femoral anteversion was $20.05^{\circ}$. The value was higher on the left side than the right a statistically significant difference. There was no significant difference between the male and female type bones though greater values were obtained in females. Average anteversion angle of femora in Bengali population is higher than that of several previous studies. Therefore, this study will be of use in the fields of orthopaedics to diagnose various lower limb pathologies and in planning of corrective surgeries, forensic medicine to establish individual identification, anthropology to determine the racial variations of the femoral anteversion.

\section{REFERENCES}

[1] Standring S. Gray's anatomy: the anatomical basis of clinical practice. 40 $0^{\text {th }} \mathrm{Ed}$. Edinburgh, Churchill Livingstone/Elsevier. 2008, 1360.

[2] Reikeras O, Bjerkreim I, Kolbenstuedt A. Anteversion of the acetabulum and femoral neck in normals and in patients with osteoarthritis of the hip. Acta Orthop Scand. 1983; 54(1): 1823.

[3] Yoshioka Y, Siu D, Cooke TD. The anatomy of functional axis of the femur. J Bone Joint Surg Am. 1987; 69(6) : 873-80.

[4] Farrally MR, Moore WJ. Anatomical differences in the femur and tibia between Negroids, Caucasians and their effects on locomotion. Am J Phys Anthropol. 1985; 43(1) : 63-69.

[5] Eckhoff DG, Kramer RC, Watkins JJ, Alongi CA, Van Gerven DP. Variation in femoral anteversion. Clin Anat. 1994; 7(2): 72-75.

[6] Stuart LW, Joseph AB. Turek's Orthopaedics principles and their application. $6^{\text {th }}$ Ed. Philadelphia, Lippincott Williams wilkins. 2005; 633-70.

[7] Ruby L, Mital MA, O'Connor J, Patel U. Anteversion of the femoral neck. J Bone Joint Surg Am. 1979; 61:46-51.

[8] Crane L. Femoral torsion and its relation to toeing-in and toeingout. J Bone Joint Surg Am. 1959; 41: 421-28.

[9] Nagar M, Bhardwaj R, Prakash R. Anteversion in adult Indian femora. J Anat Soc India. 2000; 49(1): 9-12.

[10] Ruwe PA, Gage JA, Ozonoff MB, DeLuca PA. Clinical determination of femoral anteversion. A comparison with established techniques. J Bone Joint Surg Am. 1992; 74(6):82030. 
[11] Trotter M. Estimation of stature from intact limb bones. In Stewart TD (ed.), Personal Identification in Mass Disasters. Washington DC, Smithsonian Institution Press. 1970; 71-83.

[12] Pan N. Length of long bones and their proportion to body height in Hindus. J Anat. 1924; 58(4): 374-78.

[13] Di Bennardo R, Taylor JV. Sex assessment of the femur: A test of a new method. Am J Phys Anthropol. 1979; 50(4):635-37.

[14] Wilder $\mathrm{HH}$. A laboratory manual of anthropometry. $1^{\text {st }}$ Ed. Philadelphia, Blakiston. 1920; 18:128.

[15] Jain AK, Maheswari AV, Singh MP, Nath S, Bhargava SK. Femoral neck anteversion: A comprehensive Indian study. Indian J Orthop. 2005; 39(3):137-44.

[16] Srimathi T, Muthukumar T, Anandarani VS, Umapathy S, Rameshkumar S. A study on femoral neck anteversion and its clinical correlation. J Clin Diagn Res. 2012; 6(2): 155-58.

[17] Maheshwari AV, Zlowodzki MP, Siram G, Jain AK. Femoral neck anteversion, acetabular anteversion and combined anteversion in the normal Indian adult population: A computed tomographic study. Indian journal of orthopaedics. 2010; 44(3): 277.

[18] Zalawadia A, Ruparelia S, Shah S, Parekh D, Patel S, Rathod SP, Patel SV. Study of femoral neck anteversion of adult dry femora in gujarat region. Natl J Integr Res Med. 2010;1(3): 7-11.

[19] Akkila SS, Ali AA, Abdulhussein GA. Femoral neck anteversion and hip rotation range in healthy Iraqi children: A clinical anatomical study. Mustansiriya Medical Journal.2012; 11(1): 32-36.

\section{AUTHOR(S):}

1. Dr. Moulik Debnath

2. Dr. Sudipto Konar

3. Dr. Piyali Kundu

4. Ms. Madhumita Debnath

\section{PARTICULARS OF CONTRIBUTORS:}

1. Assistant Professor, Deptartment of Anatomy, Murshidabad Medical College and Hospital, West Bengal, India.

2. Assistant Professor, Deptartment of Anatomy, Burdwan Medical College and Hospital, West Bengal.

3. Demonstrator, Dept. of Pathology, IPGMER, Kolkata, West Bengal, India.
[20] Khan WU, labal MJ, Marwat M, llahi M. Femoral neck anteversion: is the side wise difference significant? Gomal J Med Sci. 2014; 11(2):199-203.

[21] Parsons FG. The characters of the English thigh bone. J Anat Physiol. 1914;48(3):238-67.

[22] Kingsley PC, Olmsted KL. A study to determine the angle of anteversion of the neck of the femur. J Bone Joint Surg Am. 1948; 30(3):745-51.

[23] Hamill J, Knutzen KM. Biomechanical Basis of Human Movement. $1^{\text {st }}$ Ed. Baltimore, Williams \& Wilkins. 1995; 298-99.

[24] Valmassy RL. Clinical biomechanics of the lower extremity. $1^{\text {st }}$ Ed. St. Louis, Mosby-Year Book Inc. 1996; 249-50.

[25] Jain AK, Maheshwari AV, Nath S, Singh MP, Nagar M. Anteversion of the femoral neck in Indian dry femora. Journal of orthopaedic science. 2003; 8(3): 334-40.

[26] Badjatiya K, Gupta G. Angle of femoral torsion in subjects of Udaipur region, Rajasthan, India. Research and Reviews: Journal of Medical and Health Sciences. 2014; 3(1): 27-30.

[27] Lausten GS, Jorgensen F, Boesen, J. Measurement of anteversion of the femoral neck. Ultrasound and computerised tomography compared. Journal of Bone \& Joint Surgery, British Volume. 1989; 71(2): 237-39.

[28] Sugano N, Noble PC, Kamaric E. A comparison of alternative methods of measuring femoral anteversion. Journal of computer assisted tomography. 1998; 22(4): 610-14.
4. Assistant Professor, Deptartment of Physiology, Dr. Kanailal Bhattacharyya College, Howrah, West Bengal, India.

\section{NAME, ADDRESS, E-MAIL ID OF THE} CORRESPONDING AUTHOR:

Dr. Sudipto Konar,

346, Officers Colony, PO: Sripally, Burdwan,

West Bengal-713103, India.

E-mail: sudiptokonar@gmail.com

FINANCIAL OR OTHER COMPETING INTERESTS: None.

Date of Publishing: Jan 05, 2016 